treat phobias for 12 years. He believes the technology has proven valuable for research and has made for more affordable and effective mental health care, though he stresses that it is still just a tool. "The VR [virtual reality] is not going to make you a better clinician than you already are. The underlying, basic clinical skills learned in school need to be mastered."

Bouchard and his team began researching virtual reality exposure therapy in 2000. At the time, the cyberpsychology lab owned only virtual reality goggles, or head-mounted displays, which project images directly into a user's eyes.

Head-mounted displays are more affordable than immersive rooms, but are unable to create the same degree of realism. They provide a limited field of vision and don't allow users to see their own bodies while in a virtual environment. In 2005, Bouchard received funding for a 3-wall projection system. In January 2008, he received a grant from the Canadian Foundation for Innovation to upgrade that system to the $\$ 6$ million immersive room, which the lab has called PSYCHÉ. An immersive room, also known as a cave automatic virtual environment, is comprised of multiple square screens with sides about 3 metres in length. PSYCHÉ has 4 vertical screens, which serve as the walls of the virtual apartment, as well as 2 horizontal screens representing a floor and ceiling. Images are beamed onto each screen by its own projector, which is in turn operated by its own computer.

People undergoing therapy within the room are equipped with goggles that allow them to experience the virtual environment in 3 dimensions. The goggles also track movement, which enables the projectors to adjust images to reflect a patient's changing point of view.

Oddly enough, now that he has the technology to render realistic environments, Bouchard plans on using it to determine how much reality can be stripped away before virtual reality therapy becomes ineffective. The prevailing theory in cyberpsychology circles is that someone undergoing virtual reality therapy must feel a sense of presence - that is, they must feel as if they really are in, say, a plane or a

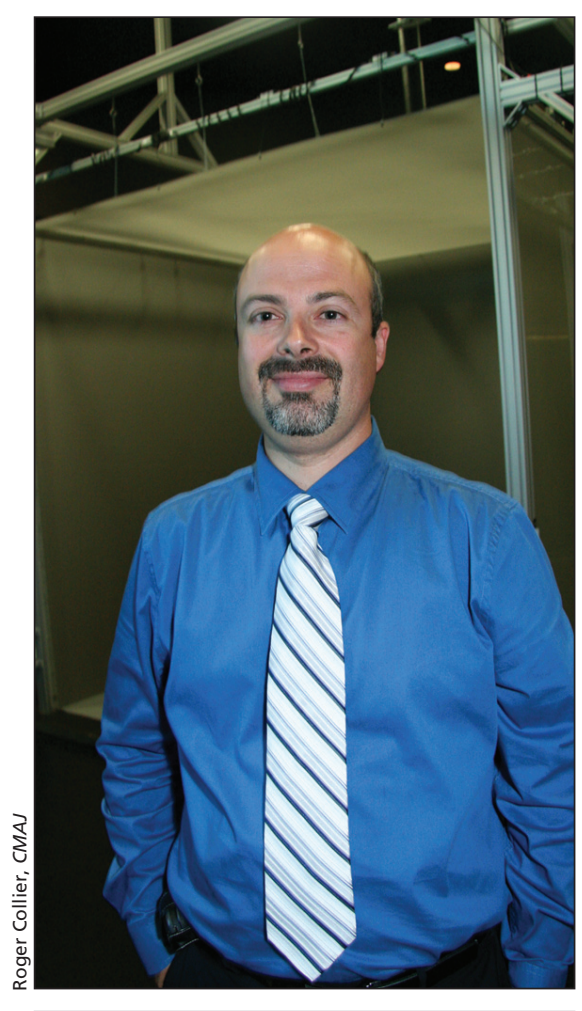

Stéphane Bouchard, the Canada Research Chair in Clinical Cyberpsychology, runs the only 6-wall virtual reality "immersive room" in the world dedicated to clinical psychology.

room full of spiders - in order for the treatment to work.

In some cases, Bouchard believes, that may not be true. To treat simple anxiety disorders, for example, the environment only needs to trigger the anxiety; certain other details may not be necessary.

"You don't need a perfect replica of reality, you need just enough," says Bouchard. "We are trying to figure out what just enough is."

Virtual reality has yet to be proven effective in treating complex problems, like post-traumatic stress disorder and obsessive-compulsive disorder. In time, however, Bouchard believes virtual reality researchers will succeed in creating the complex digital worlds needed to treat even the most complicated of mental disorders, though it may not be easy.

"There are so many situations that can trigger anxiety, so that is more of a challenge." - Roger Collier, CMAJ

DOI:10.1503/cmaj.081119

\section{Big pharma and good}

\section{corporate citizenship}

$\mathrm{T}$ he World Health Organization says that improving access to important and lifesaving medicines could save as many as 10 million lives a year. Yet in a world where a billion people live on less than $\$ 1$ a day, and important medicines consume a growing portion of the incomes of the planet's most destitute, there are no benchmarks that reveal the accessibility of medicines to the most poor. The impact of company policies on the availability of patented products in poor countries is largely unknown and it's all but a total mystery as to how much of a company's research budget is spent on discovering cures for diseases that affect the poor.

Until now, that is.

At least, that's the hope of the developers of a recently minted social responsibility index (http://atmindex. org/) that will track and measure the efforts of individual drug companies in ensuring that access to effective and affordable medicine is part of their corporate business plan.

Launched in June 2008, the index was established by the Access to Medicine Foundation, based in the Netherlands, which aims to raise awareness of the vital issue of global access to medicine by ranking 20 of the world's largest drug companies by how well they perform around 28 key indicators grouped into 8 main criteria. Those include patents, philanthropy, research and development, and pricing (Box 1). The upshot will be an "at-a-glance" snapshot of a company's social responsibility record.

Wim Leereveld, the founder and chief executive officer of the index, sees his initiative as being all about transparency. "What gets measured gets managed," he told CMAJ in an email interview. As each company becomes "transparent in what they do, or don't do, their roles will be much clearer and they will hopefully set and achieve goals for access to medicine for all."

Leereveld adds that encouraging companies to meet these goals requires the involvement of many stakeholders including governments, experts, nongovernmental organizations and others. 


\section{Box 1: Ranking big pharma}

The Access to Medicine Index seeks to measure whether the worldís major pharmaceutical firms are good corporate citizens, using 8 criteria on a scale of 1-5: management, influence, research and development, patenting, capacity, philanthropy, pricing and drug donations. In 2008, organizers assessed 20 firms. In descending order (with their ratings on the scale) they were:

1. GlaxoSmithKline PLC (4.5)

2. Novo Nordisk A/S (3.9)

3. Merck \& Company Inc. (3.9)

4. Novartis AG (3.9)

5. Sanofi-Aventis (3.9)

6. AstraZeneca PLC (3.7)

7. Roche Holdings Ltd. (3.6)

8. Johnson \& Johnson (3.6)

9. Bayer Schering Pharma AG (3.5)

10. Eli Lilly \& Company (3.5)

11. Bristol-Myers Squibb Co. (3.0)

12. Abbott Laboratories Inc. (2.9)

13. Merck KgaA AG (2.8)

14. Cipla Ltd. (2.7)

15. Gilead Sciences Inc. (2.7)

16. Ranbaxy Laboratories Ltd. (2.7)

17. Pfizer Inc. (2.6)

18. Wyeth (2.1)

19. Teva Pharmaceutical Ltd. (1.8)

20. Schering-Plough Corp. (1.3)

Source: Access to Medicine Index.

Vancouver-based corporate responsibility expert Coro Strandberg is impressed by the index's comprehensiveness and user-friendliness.

But as with other efforts to weigh corporate social responsibility, she cautioned that if the index is to grow into a trusted measuring tool, it will have to be based on data that is current and verifiable by third parties. For now, though, Strandberg stresses that it's a valuable step that the index has been launched and is freely available on the Internet to those wanting to compare the progress of major drug manufacturer's in achieving the criteria.

Leereveld forecasts that "the criteria will be sharper every year. ... I know that we have achieved goals if all measured companies have adapted their policy to the policies of leading companies."

Strandberg notes that such indices can help socially minded investors and consumers make ethical purchasing decisions and ultimately those decisions will affect the corporate behaviour of the manufacturers.
But some fear it could evolve into little more than a public relations tool for big pharma.

Tim Reed of the Amsterdam-based Health Action International is concerned that the index may just be "scratching the surface of corporate social responsibility." The bulk of the data used to construct the index is self-reported, he notes, adding that robust data provided by local consumers and patients would be a valuable addition. Yet, many would maintain that simply establishing the index has the potential to aid in drugs becoming more accessible in the developing world.

The first index identifies UK-based GlaxoSmithKline as the current industry leader when it comes to improving access to drugs and vaccines. - Alan Cassels, Victoria, BC

DOI:10.1503/cmaj.081135

Dr. Alan Cassels is a drug policy researcher at the University of Victoria and a selfdescribed pharmaceutical skeptic. His most recent book was The ABCs of Disease Mongering: An Epidemic in 26 Letters (CMAJ 2008:179[1]:58-9).

\section{Health Canada's investment in new post- market drug surveillance network a "pittance"}

Published at www.cmaj.ca on July 16, 2008. Print version revised.

I $\mathrm{n}$ the wake of mounting public concern about prescription drug safety and high-profile drug withdrawals, Health Canada has announced a \$1 million investment in an independent research network to study the safety of prescription drugs taken by Canadians.

But observers say that the investment, announced in July 2008, falls far short of what is needed. A business plan produced for the proposed network last year estimated annual operating costs to be $\$ 20.6$ million.

Parliament's Standing Committee on Health called on the government in June 2008 to "immediately" establish the network, which would link researchers around the country to produce timely reports that track the impact of drug use in the "real world" and hence help protect Canadians from the unanticipated adverse effects of prescription drugs.

Dr. Carolyn Bennett, Member of Parliament for St. Paul's, Toronto and a committee member, was "thrilled" the network is being acknowledged, but dismissed the \$1-million investment as a "pittance... just a little nod, with no assurance that another $\$ 20$ million will be forthcoming."

Post-Market Surveillance of Pharmaceuticals (June 2008), the Parliamentary committee's 54-page report, noted that Health Canada's proposed new "life cycle" approach to regulating prescription drugs (Bill C51) would ramp up the need for scrutiny of how drugs are actually used after they are approved for marketing.

Drugs are now assessed for safety and efficacy before they are approved for marketing, but the assessment is based on clinical trials conducted with limited numbers and types of patients. It is widely acknowledged that once on the market, drugs are taken by patients and disease groups that were never assessed, leaving them at risk for unexpected risks. A modern regulatory system is one that "continuously assesses a product's risks and benefits, both before and after it reaches the market," states the federal Food and Consumer Product Safety Action Plan.

Around the world, countries are moving to establish systems to track the safety and effectiveness of drugs after they are marketed, but a key stumbling block is "sheer political will, because you have to put money towards this," says internationally renowned drug researcher Dr. David Henry, who is now the president of the Institute of Clinical Evaluative Sciences in Toronto, Ontario.

"This is such an important issue. A lot of drugs seem okay and are later found to have serious adverse effects, like [rofecoxib] Vioxx [which was withdrawn from the Canadian market in 2005] and the diabetes drug [rosigli- 